\title{
HYDROTHERMAL CORROSION RESISTANCE OF SILICON NITRIDE WITH O'-SIALON GRAIN BOUNDARY PHASE
}

\author{
\#MICHAL VETRECIN*, ZOLTÁN LENČÉŠ*, DAGMAR GALUSKOVÁ**, PAVOL ŠAJGALÍK* \\ *Institute of Inorganic Chemistry, Slovak Academy of Sciences, 84536 Bratislava, Slovak Republic \\ **Vitrum Laugaricio - Joint Glass Centre of the IIC SAS, TnU AD, FChFT STU and RONA j.s.c., \\ 91150 Trenčin, Slovak Republic \\ "E-mail: vetrecinm@gmail.com
}

Submitted June 13, 2018; accepted August 7, 2018

\begin{abstract}
Keywords: Ceramic, Silicon nitride, Sialon, ICP-OES, Corrosion
Dense $\mathrm{Si}_{3} \mathrm{~N}_{4}$-based composites with O'-SiAlON bonding phase were prepared by hot pressing of the mixture of $\mathrm{Si}_{3} \mathrm{~N}_{4}$ matrix and polysiloxane (samples $S A$ ) and polysilazane (samples $S B$ ) based sintering aids. In both samples $\alpha-S i_{3} N_{4}$ and $\beta$-Si $i_{3} N_{4}$ were identified as major phases and $O^{\prime}-S i A l O N$ with a chemical formula $S i_{1.84} A l_{0.16} O_{1.16} N_{1.84}$ as a minor phase. The hydrothermal corrosion tests were performed in subcritical conditions at $250^{\circ} \mathrm{C}$ for 100 hours. The weight loss was rather low, $0.96 \mathrm{wt} . \%$ and 1.32 wt. \% for samples $S A$ and $S B$, respectively. The corrosion rate of samples $S A$ and $S B$ was $206 \mathrm{mg} \cdot \mathrm{m}^{-2} \cdot h^{-1}$ and $233 \mathrm{mg} \cdot \mathrm{m}^{-2} \cdot \mathrm{h}^{-1}$. The higher corrosion rate of sample SB prepared with polysilazane-based sintering aid is most probably due to the hydrothermal dissolution of $\mathrm{Si}_{3} \mathrm{~N}_{4}$ grains producing ammonia, as the $\mathrm{pH}$ value of eluate of this sample was higher, 8.5 compared to $\mathrm{pH}=8.0$ determined for sample $\mathrm{SA}$. In sample $\mathrm{SA}$ a continuous $\mathrm{SiO}_{2}$-based passivation layer was formed, while in sample $S B$ the passivation layer was discontinuous and the corrosion medium could easily attack the $\mathrm{Si}_{3} \mathrm{~N}_{4}$ grains. As the corrosion solution was more basic in sample $\mathrm{SB}$, the $\mathrm{SiO}_{2}$ passivation layer did not form so effectively, or dissolved faster than in sample SA. The higher corrosion resistance of sample $\mathrm{SA}$ was partly improved also by using $\mathrm{Y}_{2} \mathrm{O}_{3}$ sintering additive, which formed a rather stable $\mathrm{Y}_{2} \mathrm{SiO}_{5}$ phase.
\end{abstract}

\section{INTRODUCTION}

Silicon nitride and SiAlON-based ceramics have a wide spread structural applications due to their excellent mechanical properties like strength and fracture toughness, good thermal shock and creep resistance, good tribological and wear properties [1]. These properties predestine the $\mathrm{Si}_{3} \mathrm{~N}_{4}$-based ceramics for applications such as engine components, heat exchangers, pump seal materials, ball bearings, cutting tools, etc. However, recently there is an increasing demand on materials, which can withstand attack by hot aqueous solutions for applications in geothermal production units (heat exchangers, pumps, armatures), subcritical and supercritical water oxidation units for waste management, hydrolysis or gasification of biological substances, units for the desalination of seawater, etc. [2-4]. Several studies have shown that the hydrothermal corrosion resistance of $\mathrm{Si}_{3} \mathrm{~N}_{4}$-based materials is rather low [5-14]. The general conclusion was that the oxidation rate of $\mathrm{Si}_{3} \mathrm{~N}_{4}$ by hot water vapour depends on the sintering aids, sintering process, porosity and impurities [8]. In our previous work on the hydrothermal corrosion of $\mathrm{Si}_{3} \mathrm{~N}_{4}$ and $\mathrm{SiAlON}$ it was observed that the $\mathrm{Si}-\mathrm{N}$ bonds in $\mathrm{Si}_{3} \mathrm{~N}_{4}$ and both the $\mathrm{Si}-\mathrm{N}$ and $\mathrm{Al}-\mathrm{N}$ bonds in SiAlON are attacked preferentially resulting in severe pitting corrosion [15].
The hydrothermal oxidation of $\mathrm{Si}_{3} \mathrm{~N}_{4}$ can be described by the following general equation [7]:

$$
\mathrm{Si}_{3} \mathrm{~N}_{4}+6 \mathrm{H}_{2} \mathrm{O}=3 \mathrm{SiO}_{2}+4 \mathrm{NH}_{3}
$$

The oxidation/corrosion resistance of $\mathrm{Si}_{3} \mathrm{~N}_{4}$ ceramics can be enhanced by appropriate selection of sintering aids, e.g. using rare-earth oxides $\left(\mathrm{Y}_{2} \mathrm{O}_{3}, \mathrm{Yb}_{2} \mathrm{O}_{3}\right.$, $\mathrm{Lu}_{2} \mathrm{O}_{3}$ ) to create a corrosion resistant grain boundary phase or crystalline silicates at the triple junctions [16]. It is known that the grain boundary phase and triple point phases play a critical role on high-temperature properties of $\mathrm{Si}_{3} \mathrm{~N}_{4}$ ceramics, including their oxidation and corrosion resistance $[13,17]$. Therefore, high attention should be paid also to the design of the grain boundaries composition, i.e. to the selection of sintering additives. Linck et al. has reported a very good hydrothermal corrosion resistance of polymer-derived silicon oxycarbide-based ceramics (SiOC, SiZrOC and SiHfOC) [18]. In our earlier work we have used the preceramic SiAlOC polymer-derived ceramic (PDC) material as a sintering aid for the densification of $\mathrm{Si}_{3} \mathrm{~N}_{4}$ and the material showed good mechanical proper-ties with a hardness of $19 \mathrm{GPa}$ and fracture toughness $5 \mathrm{MPa} \cdot \mathrm{m}^{1 / 2}$ [19].

In this work we have studied the hydrothermal corrosion resistance of $\mathrm{Si}_{3} \mathrm{~N}_{4} / \mathrm{O}$ '-SiAlON-based composites in subcritical water at $250^{\circ} \mathrm{C}$. The composites were 
prepared by hot pressing of the mixture of $\mathrm{Si}_{3} \mathrm{~N}_{4}$ matrix and SiAlOCN-based polymer-derived ceramic sintering aids.

\section{EXPERIMENTAL}

Preparation of the sintering additives

Commercial $\alpha-\mathrm{Si}_{3} \mathrm{~N}_{4}$ powder (SN-E10, Ube Industries Ltd., Tokyo, Japan, $\alpha$-phase $\left.>95 \%, d_{50}=0.5 \mu \mathrm{m}\right)$ was used as a matrix for the preparation of $\mathrm{Si}_{3} \mathrm{~N}_{4}$-based composites. Two types of sintering aids have been used, both were composed of preceramic polymers combined with very fine inorganic fillers (Table 1). The preparation of sintering aids is described in details elsewhere [19]. Briefly, the sintering additive A was prepared from the mixture of polysiloxane (Silres H44, Wacker-Chemie $\mathrm{GmbH}$, Müchen, Germany), $\gamma-\mathrm{Al}_{2} \mathrm{O}_{3}$ (Aeroxide $\mathrm{Alu} \mathrm{C}$, Evonik Industries AG, Essen, Germany, $d_{50}=13 \mathrm{~nm}$ ), amorphous $\mathrm{Si}_{3} \mathrm{~N}_{4}$ (Goodfellow, Huntingdon, England, $d_{50}=20 \mathrm{~nm}$ ), carbon black (Vulcan XC-72, Cabot, Leuven, Belgium, mean particle size of $20-50 \mathrm{~nm}$ ) and $\mathrm{Y}_{2} \mathrm{O}_{3}$ (Inframat Advanced Materials, Manchester, CT, USA, mean particle size of $30-50 \mathrm{~nm}$ ) in isopropyl alcohol. The homogenized slurry was dried for $8 \mathrm{~h}$ at $60^{\circ} \mathrm{C}$. The fillers were active, because they formed a SiAlON-based solid solution during sintering. Carbon acted as a reducing agent to produce in situ AlN from $\gamma-\mathrm{Al}_{2} \mathrm{O}_{3}$, which was incorporated into the structure of SiAlON. $\mathrm{Y}_{2} \mathrm{O}_{3}$ served as a common sintering aid and should decrease the viscosity of SiAlON-based liquid phase during sintering.

The sintering aid B was prepared from the mixture of polysilazane precursor (Ceraset PSZ20, KiON Defense Technologies Inc., Huntigdon Valley, PA, USA) and $\gamma-\mathrm{Al}_{2} \mathrm{O}_{3}$ nanopowder (Aeroxide $\mathrm{Alu} \mathrm{C}$ ) in hexane. After drying the mixture was crosslinked at $300^{\circ} \mathrm{C}$ for 1 $\mathrm{h}$ and pre-pyrolysed at $600^{\circ} \mathrm{C}$ for $30 \mathrm{~min}$ in flowing $\mathrm{N}_{2}$. Finally, the heat treated powder mixtures $\mathrm{A}$ and $\mathrm{B}$ were separately ball milled in $\mathrm{Si}_{3} \mathrm{~N}_{4}$ milling container with $\mathrm{Si}_{3} \mathrm{~N}_{4}$ balls.

\section{Preparation of composites}

The starting powders for the preparation of $\mathrm{Si}_{3} \mathrm{~N}_{4}$ based composites were composed of $82 \mathrm{wt} . \%$ of $\alpha-\mathrm{Si}_{3} \mathrm{~N}_{4}$ (SN-E10, Ube Ind. Ltd., Japan) and 18 wt. \% of sintering additives (A or B, Table 1). The powder mixtures were homogenized in a $\mathrm{Si}_{3} \mathrm{~N}_{4}$-based planetary ball mill in hexane and after rotary evaporation of solvent dried in vacuum drier at $80^{\circ} \mathrm{C}$ and $200 \mathrm{mbar}$ for $6 \mathrm{~h}$. Soft agglomerates were crushed in agate mortar. From the prepared powders pellets $(\varphi=12 \mathrm{~mm})$ were pressed by uniaxial pressing (100 MPa).

Samples were densified in a graphite resistance hot-pressing furnace. The sintering conditions and densification behaviour of the produced samples are summarized in Table 2. Due to the lower viscosity of polysiloxane-based additives samples SA could be densified at lower temperature and shorter time $\left(1600^{\circ} \mathrm{C} / 15 \mathrm{~min}\right)$ compared to samples SB containing polysilazane-based additives with higher viscosity $\left(1700^{\circ} \mathrm{C} / 30 \mathrm{~min}\right)$. The load of $30 \mathrm{MPa}$ was applied at $1200^{\circ} \mathrm{C}$ during the heating up to the final processing temperature and released at $1300^{\circ} \mathrm{C}$ during cooling. Nitrogen gas inlet started at $300^{\circ} \mathrm{C}$ and was adjusted to constant $0.105 \mathrm{MPa}$ in the furnace during the whole experiment.

Table 2. Hot pressing conditions (temperature $T$, dwell time $t_{d}$, load $P$ ) and weight loss $(\Delta m)$ of samples SA and SB.

\begin{tabular}{lcccc}
\hline Samples & $T_{\max }\left({ }^{\circ} \mathrm{C}\right)$ & $t_{d}(\min )$ & $P(\mathrm{MPa})$ & $\Delta m(\%)$ \\
\hline SA & 1600 & 15 & 30 & -5.87 \\
SB & 1700 & 30 & 30 & -4.33 \\
\hline
\end{tabular}

\section{Materials characterization}

Density measurements were carried out by the Archimedes method in mercury. Each sintered sample was measured three times and the standard deviation of density values was less than $0.02 \mathrm{~g} \cdot \mathrm{cm}^{-3}$. The microstructures were observed by scanning electron microscopy (EVO 40HV; Zeiss, Oberkochen, Germany). Phase composition was investigated by X-ray diffraction analysis (D8-Discover; Bruker, Madison, WI, CuK $\alpha$ radiation), and applying the X'Pert HighScore Plus 3.0 software (PANalytical, Inc., Westborough, MA).

Vickers hardness and indentation fracture resistance were measured using Leco hardness tester (LV-100, Leco Co., St. Joseph, MI) by indentation method applying a load of $9.8 \mathrm{~N}$ and $98 \mathrm{~N}$, respectively. The indentation fracture resistance was calculated according to Shetty's equation [20]:

$$
K_{I C}=0.0889(H \cdot P / 4 l)^{0.5}
$$

where $H$ is the hardness, $P$ is the applied load, and $l$ is the crack length.

Table 1. Composition of preceramic-polymer-based sintering additives.

\begin{tabular}{ccccccc}
\hline $\begin{array}{c}\text { Powder } \\
\text { mixture }\end{array}$ & $\begin{array}{c}\mathrm{H} \text { polysiloxane } \\
(\text { wt. \%) }\end{array}$ & $\begin{array}{c}\mathrm{HTT} \\
\text { polysiloxan } \\
(\text { wt. \%) }\end{array}$ & $\begin{array}{c}\gamma-\mathrm{Al}_{2} \mathrm{O}_{3} \\
(\text { wt. \%) }\end{array}$ & $\begin{array}{c}\text { a- } \mathrm{Si}_{3} \mathrm{~N}_{4} \\
(\text { wt. \%) }\end{array}$ & $\begin{array}{c}\mathrm{C} \\
\text { (wt. \%) }\end{array}$ & $\begin{array}{c}\mathrm{Y}_{2} \mathrm{O}_{3} \\
(\text { wt. \%) }\end{array}$ \\
\hline $\mathrm{A}$ & 35.7 & - & 37.1 & 21.6 & 1.1 & 4.4 \\
$\mathrm{~B}$ & - & 67.0 & 33.0 & - & - & - \\
\hline
\end{tabular}


Corrosion experiments under static conditions

The sintered samples were cut and ground to rectangular bars. Their faces were polished with $3 \mu \mathrm{m}$ diamond paste and the edges were chamfered. The bars were ultrasonically cleaned in acetone for $15 \mathrm{~min}$, rinsed in distilled water and dried in vacuum drier at $80^{\circ} \mathrm{C}$ for $12 \mathrm{~h}$.

As the reference medium deionized water was used (conductivity $25 \pm 5 \times 10^{-4} \mathrm{~S} \cdot \mathrm{m}^{-1}$ prepared in the reverse osmosis purification system (CHEZAR, Bratislava, Slovak Republic). The bars were placed in teflon-lined pressure corrosion reactors with the inside volume $26 \mathrm{~cm}^{3}$ filled with corrosion liquid of $\mathrm{pH} 7.4$ and heated in laboratory drying oven. The ratio between the sample surface and the volume of corrosive liquid $(S / V)$ was held constant at $0.17 \pm 0.05 \times 10^{-3} \mathrm{~cm}^{-1}$. The corrosion tests were carried out at $250^{\circ} \mathrm{C}$ (pressure cca $3.9 \mathrm{MPa}$ ) for 100 hours. The weight of bars and $\mathrm{pH}$ value of corrosion medium were measured before and after each corrosion test.

\section{RESULTS AND DISCUSSION}

\section{Microstructure and phase composition}

All samples were densified to nearly full density with a remaining porosity on the level of $1-2 \%$. Based on the XRD and SEM analysis (Figure 1) in both SA and SB samples $\alpha-\mathrm{Si}_{3} \mathrm{~N}_{4}, \beta-\mathrm{Si}_{3} \mathrm{~N}_{4}$ and O'-SiAlON (general formula $\mathrm{Si}_{2-x} \mathrm{Al}_{x} \mathrm{O}_{1+x} \mathrm{~N}_{2-x}$, where $0.04 \leq x \leq 0.4$ [21]) were detected as the major phases. The X-ray diffraction data were evaluated by Rietveld refinement using the X'Pert HighScore Plus 3.0 software. The crystallographic information file (CIF) of $\mathrm{Si}_{1.84} \mathrm{Al}_{0.16} \mathrm{O}_{1.16} \mathrm{~N}_{1.84}$ phase was used for O'-SiAlON, i.e. with $x=0.16$ in a general formula $\mathrm{Si}_{2}$ ${ }_{x} \mathrm{Al}_{x} \mathrm{O}_{1+x} \mathrm{~N}_{2-x}$, as this phase fitted the best to the obtained

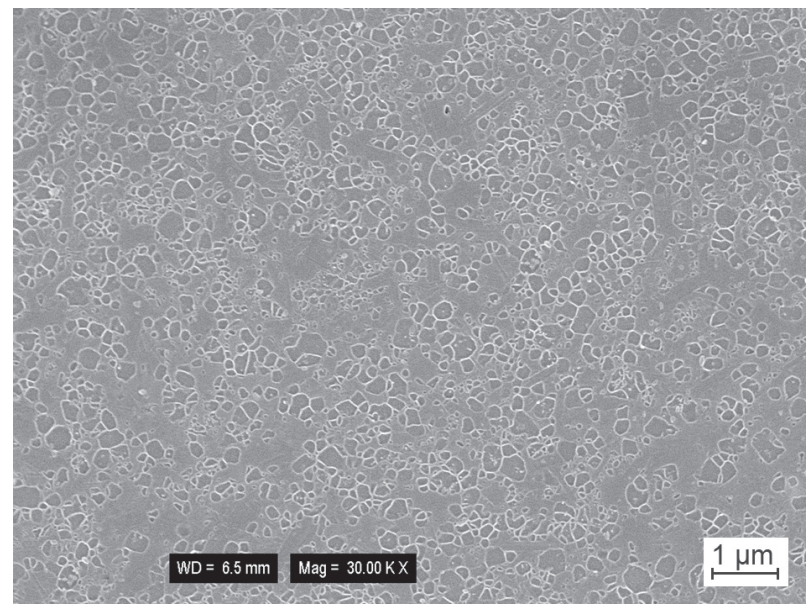

a) SA diffractions. The results of quantitative phase analysis are listed in Table 3. The main difference is in the content of $\alpha$ and $\beta-\mathrm{Si}_{3} \mathrm{~N}_{4}$, as the $\mathrm{O}^{\prime}-\mathrm{SiAlON}$ content was around $19-24 \%$. While in sample SA the ratio $\alpha /(\alpha+\beta) \mathrm{Si}_{3} \mathrm{~N}_{4}$ was $69.7 \%$, in sample SB it was only $34.7 \%$. The higher $\beta-\mathrm{Si}_{3} \mathrm{~N}_{4}$ content in sample $\mathrm{SB}$ is caused by the higher sintering temperature $\left(1700^{\circ} \mathrm{C}\right)$, longer dwell time (30 $\mathrm{min})$ and "nitrogen-rich" polysilazane-based sintering aid. All these parameters enhance the $\alpha \rightarrow \beta-\mathrm{Si}_{3} \mathrm{~N}_{4}$ phase transformation. The size of $\alpha-\mathrm{Si}_{3} \mathrm{~N}_{4}$ grains in sample SA was approximately $0.3 \mu \mathrm{m}$ and in sample SB their size was a little bit smaller, $0.1-0.2 \mu \mathrm{m}$ (more etched grains are $\alpha-\mathrm{Si}_{3} \mathrm{~N}_{4}$ in the microstructures in Figure 1). The O'-SiAlON phase is homogeneously distributed on the grain boundaries and in triple junctions (unetched areas in Figures 1a, b). There is a remarkable difference in the grain size of $\beta-\mathrm{Si}_{3} \mathrm{~N}_{4}$ due to the higher sintering temperature and longer holding time applied during the sintering of sample SB. The needle-like elongated $\beta-\mathrm{Si}_{3} \mathrm{~N}_{4}$ grains are well visible in this sample (Figure 1b) having a length of $1-2 \mu \mathrm{m}$ and width of about $0.2-0.4 \mu \mathrm{m}$.

Table 3. XRD phase composition of sintered samples including the ratio of $\alpha$ and $\beta-\mathrm{Si}_{3} \mathrm{~N}_{4}$ phases $\alpha /(\alpha+\beta)$.

\begin{tabular}{lcccc}
\hline & $\begin{array}{c}\alpha-\mathrm{Si}_{3} \mathrm{~N}_{4} \\
(\%)\end{array}$ & $\begin{array}{c}\beta-\mathrm{Si}_{3} \mathrm{~N}_{4} \\
(\%)\end{array}$ & $\begin{array}{c}\mathrm{O}^{\prime}-\mathrm{SiAlON} \\
(\%)\end{array}$ & $\begin{array}{c}\alpha /(\alpha+\beta) \\
(\%)\end{array}$ \\
\hline SA & 56.6 & 24.6 & 18.8 & 69.7 \\
SB & 26.2 & 49.4 & 24.3 & 34.7 \\
\hline
\end{tabular}

\section{Properties of sintered samples}

The sintered samples were nearly fully dense with a remaining porosity of $1-2 \%$. The Vickers hardness was rather high for the prepared $\mathrm{Si}_{3} \mathrm{~N}_{4}$-based materials, close to $19 \mathrm{GPa}$ (Table 4). The hardness of $\alpha-\mathrm{Si}_{3} \mathrm{~N}_{4}$

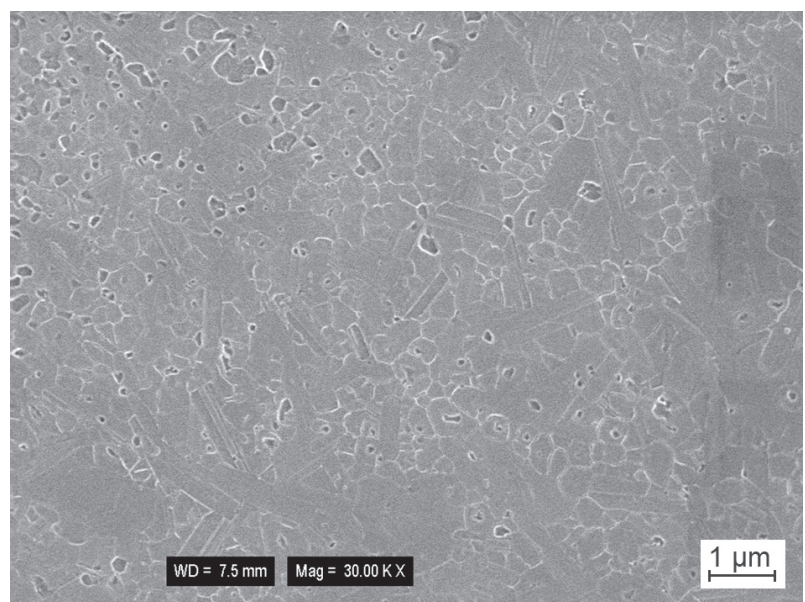

b) $\mathrm{BA}$

Figure 1. SEM micrographs of the plasma-etched cross-sections of sintered samples SA (a) and SB (b). 
$(H V \approx 20-21 \mathrm{GPa})$ and $\mathrm{O}^{\prime}-\operatorname{SiAlON}(H V \approx 16-17 \mathrm{GPa})$ is higher compared to $\beta-\mathrm{Si}_{3} \mathrm{~N}_{4}(H V \approx 15-16 \mathrm{GPa})$. For that reason the hardness of sample $\mathrm{SA}$ is higher, as it contains in total larger amount of these harder phases (cf. Table 3). Surprisingly, the indentation fracture resistance of sample SB is slightly lower compared to sample SA, although it contains larger amount of $\beta-\mathrm{Si}_{3} \mathrm{~N}_{4}$ with an elongated shape of grains (Figure 1b). Slight decrease of fracture resistance might be due to the larger content of brittle O'-SiAlON phase (24.3\%).

Table 4. Density $(\rho)$, Vickers hardness $(H V)$ and indentation fracture resistance $\left(K_{I C}\right)$ of samples SA and SB.

\begin{tabular}{lccc}
\hline Samples & $\begin{array}{c}\rho \\
\left(\mathrm{g} \cdot \mathrm{cm}^{-3}\right)\end{array}$ & $\begin{array}{c}H V \\
(\mathrm{GPa})\end{array}$ & $\begin{array}{c}K_{I C} \\
\left(\mathrm{MPa} \cdot \mathrm{m}^{1 / 2}\right)\end{array}$ \\
\hline SA & 3.11 & $19.0 \pm 0.1$ & $5.07 \pm 0.12$ \\
SB & 3.09 & $18.4 \pm 0.6$ & $4.74 \pm 0.15$ \\
\hline
\end{tabular}

Properties after hydrothermal corrosion

Both samples SA and SB exhibited a good hydrothermal corrosion resistance. The measured weight loss in sample SA after the hydrothermal corrosion test at $250^{\circ} \mathrm{C}$ for 100 hours was 0.96 wt. \%. In sample SB the weight loss was higher, 1.32 wt. \% (Table 5). The $\mathrm{pH}$ value of corrosion media changed from neutral to

Table 5. The results of hydrothermal corrosion tests of samples SA and SB at $200^{\circ} \mathrm{C}$ for 100 hours.

\begin{tabular}{lcccc}
\hline Samples & $\begin{array}{c}\Delta m \\
(\text { wt. \% })\end{array}$ & $\begin{array}{c}\mathrm{pH} \\
(\mathrm{GPa})\end{array}$ & $\begin{array}{c}\Delta m / A \\
\left(\mathrm{mg} \cdot \mathrm{cm}^{-2}\right)\end{array}$ & $\begin{array}{c}\text { rate } \\
\left(\mathrm{mg} \cdot \mathrm{m}^{-2} \cdot \mathrm{h}^{-1}\right)\end{array}$ \\
\hline SA & -0.96 & 8.0 & 2.05 & 205.5 \\
SB & -1.32 & 8.5 & 2.33 & 233.4 \\
\hline
\end{tabular}

alkaline after the corrosion test, concretely to 8.0 in sample SA and 8.5 in sample SB.

There are several factors which could cause the differences in corrosion rate of samples SA and SB. The first is the phase composition, especially the much higher $\alpha-\mathrm{Si}_{3} \mathrm{~N}_{4}$ and lower O'-SiAlON content in sample SA compared to sample SB (Table 3). It is known that the lattice oxygen content is much lower in $\beta-\mathrm{Si}_{3} \mathrm{~N}_{4}$ than in $\alpha-\mathrm{Si}_{3} \mathrm{~N}_{4}$ [22]. Although it is not necessary that $\alpha-\mathrm{Si}_{3} \mathrm{~N}_{4}$ contain oxygen to stabilize its structure, it can accommodate a considerable amount of oxygen [22]. It was found that at $1400^{\circ} \mathrm{C} \mathrm{ca} .0 .8 \pm 0.2 \mathrm{wt} . \%$ oxygen can dissolve in $\alpha-\mathrm{Si}_{3} \mathrm{~N}_{4}$ [23]. The highest oxygen solubility measured in $\beta-\mathrm{Si}_{3} \mathrm{~N}_{4}$ single crystal is $0.26 \mathrm{wt}$ \% [24]. Oda at al. have investigated the hydrothermal corrosion of pure, hot isostatically pressed $\mathrm{Si}_{3} \mathrm{~N}_{4}$ (containing 1.4 wt. $\% \mathrm{O}$ as an impurity) and observed a weight loss of $9-12 \mathrm{mg} \cdot \mathrm{cm}^{-2}$ after the corrosion test at $300^{\circ} \mathrm{C}$ and pressure 8.6 MPa for 96 hours [7]. They have observed that the amorphous $\mathrm{SiO}_{2}$ on the grain boundaries was more readily dissolved into solution than the $\mathrm{Si}_{3} \mathrm{~N}_{4}$ grains and the aqueous corrosion of $\mathrm{Si}_{3} \mathrm{~N}_{4}$ was categorized as intergranular corrosion. In our earlier work we have observed a lower corrosion rate for dense $\mathrm{Si}_{3} \mathrm{~N}_{4}$ with 5 wt. $\% \mathrm{Y}_{2} \mathrm{O}_{3}$ sintering additive and the weight loss was $1.0 \pm 0.2 \mathrm{mg} \cdot \mathrm{cm}^{-2}$ after 100 hours of hydrothermal corrosion at $290^{\circ} \mathrm{C}$ [15]. It seems that amorphous silica was the weakest compound in the above mentioned hydrothermal corrosion tests of $\mathrm{Si}_{3} \mathrm{~N}_{4}$. The solubility of $\mathrm{SiO}_{2}$ in water is temperature and pressure dependent and it is higher for amorphous silica $\left(\mathrm{a}-\mathrm{SiO}_{2}\right)$ compared to crystalline phase. The solubility of a- $\mathrm{SiO}_{2}$ at $97^{\circ} \mathrm{C}$ and $340{ }^{\circ} \mathrm{C}$ is $415 \mathrm{mg} \cdot \mathrm{l}^{-1}$ and $1660 \mathrm{mg} \cdot \mathrm{l}^{-1}$, respectively [25]. Considering the linear relationship in the dependence of $\log$ of dissolution rate vs. $1 / T$, the estimated solubility of $\mathrm{a}-\mathrm{SiO}_{2}$ at $250^{\circ} \mathrm{C}$ is about $1150 \mathrm{mg} \cdot \mathrm{l}^{-1}$. Perera et al. [26] showed that during the hydrothermal corrosion tests of silicate glasses water penetrates into the surface layers of the $\mathrm{Si}-\mathrm{O}$ lattice and reacts with $\mathrm{Si}-\mathrm{O}$ bonds:

$$
\mathrm{Si}-\mathrm{O}-\mathrm{Si}+\mathrm{H}_{2} \mathrm{O}=\mathrm{SiOH}+\mathrm{HOSi}
$$

These bond-breaking reactions destroy the structure and the silicate islands dissolve in water and form orthosilicic acid according to reaction:

$$
\begin{aligned}
& \mathrm{SiO}_{2}+2 \mathrm{H}_{2} \mathrm{O} \leftrightarrow \mathrm{H}_{4} \mathrm{SiO}_{4} \leftrightarrow \mathrm{H}_{3} \mathrm{SiO}_{4}^{-}+ \\
& +\mathrm{H}^{+} \leftrightarrow \mathrm{H}_{2} \mathrm{SiO}_{4}^{2-}+2 \mathrm{H}^{+}
\end{aligned}
$$

Such a corrosion could take part in a certain extent also in our samples, especially in sample SA with higher oxygen content. However, reaction (4) decreases the $\mathrm{pH}$ of corrosion solution and we have observed an increase of $\mathrm{pH}$ to 8 and 8.5 for sample $\mathrm{SA}$ and $\mathrm{SB}$, respectively. The $\mathrm{pH}$ value can increase by the dissolution of $\mathrm{Si}_{3} \mathrm{~N}_{4}$ in water yielding ammonia according to reaction (1), or summarized reactions (1) and (4) [27]:

$$
\mathrm{Si}_{3} \mathrm{~N}_{4}+12 \mathrm{H}_{2} \mathrm{O}=3 \mathrm{Si}(\mathrm{OH})_{4}+4 \mathrm{NH}_{3}
$$

Ammonia is a weak base highly soluble in water and increases the $\mathrm{pH}$ of eluate. This might be a reason, why the $\mathrm{pH}$ value of the corrosion medium of sample SB was higher. While sample SA contained polysiloxane-based $(\mathrm{Si}-\mathrm{C}-\mathrm{O})$ precursor as sintering additive, in sample SB nitrogen/rich polysilazane-based $(\mathrm{Si}-\mathrm{C}-\mathrm{N})$ precursor was used. This resulted in a higher content of $\beta-\mathrm{Si}_{3} \mathrm{~N}_{4}$ in the sintered product and according to reactions (1) and/ or (5) more ammonia formed and dissolved in subcritical water and increased the $\mathrm{pH}$ value of corrosion medium. Although the hydrothermal corrosion of both samples SA and SB was low, the weight loss of sample SB was approximately by $38 \%$ higher than in sample SA. The higher weight loss and higher $\mathrm{pH}$ value of corrosion medium in the case of sample SB gives a hints that reactions (1) and (5) prevail during the hydrothermal corrosion of $\mathrm{Si}_{3} \mathrm{~N}_{4}$-based samples in subcritical water.

The SEM study of the corroded samples shows that in sample SA very fine, almost continuous $\mathrm{SiO}_{2}$ corro- 
sion layer was formed (Figure 2), which slows down the dissolution of the sample. In sample SB the corrosion layer consisted of whisker-like grains, copying the structure of original elongated $\beta-\mathrm{Si}_{3} \mathrm{~N}_{4}$ grains (Figure 3 ). In this case the corrosion layer was not compact and did not separate the sample surface from the corrosion media. The solubility of $\mathrm{SiO}_{2}$ is much lower in neutral and in acidic solutions than in basic solutions [28]. In the case of sample $\mathrm{SB}$ the $\mathrm{pH}$ value of eluate was higher (8.5) and the $\mathrm{SiO}_{2}$ passivating layer did not form so effectively than in sample $\mathrm{SA}$ with lower $\mathrm{pH}$ value (8.0). The lower weight loss during the corrosion tests of sample SA might be influenced also by the use of $\mathrm{Y}_{2} \mathrm{O}_{3}$ sintering aid, which increases the corrosion resistance of $\mathrm{Si}_{3} \mathrm{~N}_{4}$ under hydrothermal conditions [29].

The corrosion rate of $\mathrm{Si}_{3} \mathrm{~N}_{4}$ powder (grade LC $12 \mathrm{~N}$, s.s.a. $=17 \mathrm{~m}^{2} \cdot \mathrm{g}^{-1}$, H.C. Stack) in water at $300^{\circ} \mathrm{C}$ determined

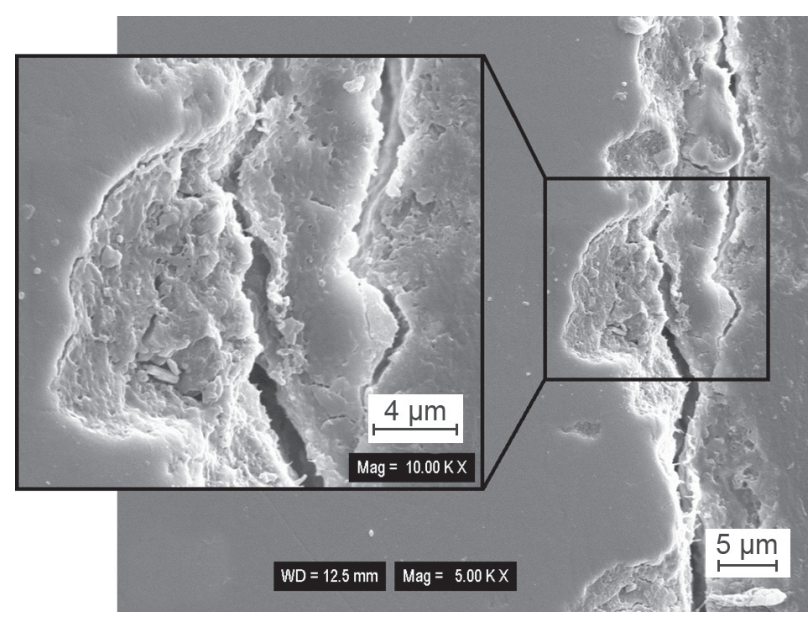

Figure 2. SEM analysis of SA after corrosion test.

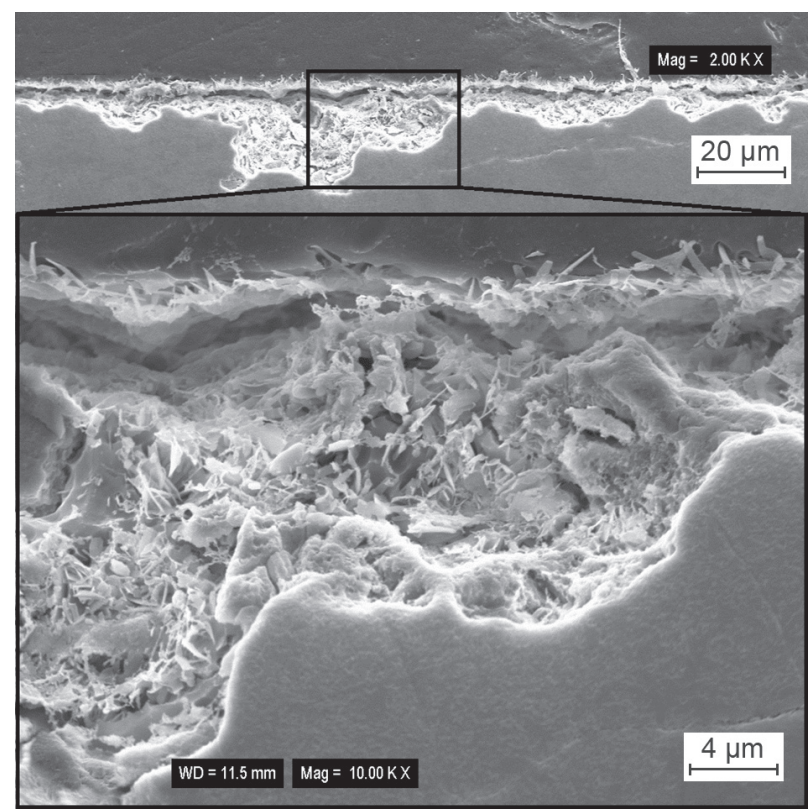

Figure 3. SEM analysis of sample SB after corrosion test. by Nickel et al. [30] was in the range of $190 \pm 70 \mathrm{mg} \cdot \mathrm{m}^{-2} \cdot \mathrm{h}^{-1}$ and that of dense $\mathrm{Si}_{3} \mathrm{~N}_{4}$ with 5 wt. $\% \mathrm{Y}_{2} \mathrm{O}_{3}$ sintering additive measured at $290^{\circ} \mathrm{C}$ in our earlier work from the leached amount of nitrogen was $210 \pm 2 \mathrm{mg} \cdot \mathrm{m}^{-2} \cdot \mathrm{h}^{-1}$ [15]. The corrosion rate of samples $\mathrm{SA}$ and $\mathrm{SB}$ in this work at $250^{\circ} \mathrm{C}$ was $206 \mathrm{mg} \cdot \mathrm{m}^{-2} \cdot \mathrm{h}^{-1}$ and $233 \mathrm{mg} \cdot \mathrm{m}^{-2} \cdot \mathrm{h}^{-1}$ (Table 5), respectively. Although the listed corrosion rates are similar, the values cannot be compared due to the different testing temperatures and also due to the different ratio of the sample surface $(S)$ to the volume of corrosion media $(V)$. If we compare only dense $\mathrm{Si}_{3} \mathrm{~N}_{4}$ based samples, then in the work of Galuskova et al. [15] the ratio $S / V$ was 0.7 , while in this work due to the smaller size of tested samples the ratio was lower, 0.17. Yuan et al. [31] have studied the influence of $S / V$ ratio on the hydrothermal corrosion of SiCN-based ceramic composites and reported that with decreasing $S / V$ ratio the weight loss increased. Therefore, higher weight loss is expected for samples $\mathrm{SA}$ and $\mathrm{SB}$ at $290^{\circ} \mathrm{C}$ with $\mathrm{S} / \mathrm{V}$ ratio 0.17 compared to the corrosion rate of samples with $S / V$ ratio 0.7 , as their corrosion rate was similar to these samples already at $250^{\circ} \mathrm{C}$.

Finally it can be concluded that both samples SA and $\mathrm{SB}$ composed of $\alpha-\mathrm{Si}_{3} \mathrm{~N}_{4}, \beta-\mathrm{Si}_{3} \mathrm{~N}_{4}$ and O'-SiAlON phases have a good corrosion resistance in subcritical water at $250^{\circ} \mathrm{C}$.

\section{CONCLUSIONS}

Dense $\mathrm{Si}_{3} \mathrm{~N}_{4} / \mathrm{O}$ '-SiAlON-based composites were prepared by hot pressing of the mixture of $\mathrm{Si}_{3} \mathrm{~N}_{4}$ matrix and two different SiAlOCN-based polymer-derived ceramic sintering aids. The first type of sintering aid was on the base of polysiloxane containing amorphous $\mathrm{Si}_{3} \mathrm{~N}_{4}, \gamma-\mathrm{Al}_{2} \mathrm{O}_{3}$ and $\mathrm{Y}_{2} \mathrm{O}_{3}$ nanopowders (sample $\mathrm{SA}$ ), the second one on the base of polysilazane and $\gamma-\mathrm{Al}_{2} \mathrm{O}_{3}$ (sample SB). In both sintered samples except of $\alpha-\mathrm{Si}_{3} \mathrm{~N}_{4}$ and $\beta-\mathrm{Si}_{3} \mathrm{~N}_{4}$ also $\mathrm{O}^{\prime}-\mathrm{SiAlON}$ with a chemical formula $\mathrm{Si}_{1.84} \mathrm{Al}_{0.16} \mathrm{O}_{1.16} \mathrm{~N}_{1.84}$ was identified, but in different proportions.

The hydrothermal corrosion tests in subcritical water at $250^{\circ} \mathrm{C}$ for $100 \mathrm{~h}$ showed a different corrosion rate for the two composites. Although the weight losses were rather low, $0.96 \mathrm{wt}$. \% for sample SA and $1.32 \mathrm{wt}$. \% for sample SB, the hydrothermal corrosion of later sample was higher by $38 \%$. The corrosion rate of samples SA and $\mathrm{SB}$ at $250^{\circ} \mathrm{C}$ was $206 \mathrm{mg} \cdot \mathrm{m}^{-2} \cdot \mathrm{h}^{-1}$ and $233 \mathrm{mg} \cdot \mathrm{m}^{-2} \cdot \mathrm{h}^{-1}$, respectively. The higher corrosion rate of sample $\mathrm{SB}$ prepared with polysilazane-based sintering aid is most probably due to the hydrothermal dissolution of $\mathrm{Si}_{3} \mathrm{~N}_{4}$ grains producing ammonia, as the $\mathrm{pH}$ value of eluate of this sample was higher, 8.5 compared to $\mathrm{pH}=8.0$ determined for sample SA. In sample SA a continuous $\mathrm{SiO}_{2}$-based passivating layer was formed, while in sample SB the corrosion layer was discontinuous and the corrosion medium could attack the $\mathrm{Si}_{3} \mathrm{~N}_{4}$ grains. As 
the corrosion solution was more basic in sample SB, the $\mathrm{SiO}_{2}$ passivating layer did not form so effectively, or dissolved faster than in sample SA. The higher corrosion resistance of sample SA was partly influenced/improved also by using $\mathrm{Y}_{2} \mathrm{O}_{3}$ sintering additive, which formed a rather stable $\mathrm{Y}_{2} \mathrm{SiO}_{5}$ phase.

Acknowledgments

This work was supported by Slovak Grant Agencies APVV-14-0385 and VEGA 2/0164/18.

\section{REFERENCES}

1. Riley F.L. (2004): Silicon nitride and related materials. Journal of the American Ceramic Society, 83(2), 245-265. doi: 10.1111/j.1151-2916.2000.tb01182.x.

2. Nagae M., Yoshio T., Oda K. (2006): Corrosion Behaviour of Structural Ceramics in Supercritical Water. Advances in Science and Technology, 45, 173-177. doi: 10.4028/www. scientific.net/AST.45.173.

3. Weingärtner H., Franck E.U. (2005): Supercritical water as a solvent. Angewandte Chemie International Edition, 44(18), 2672-2692. doi: 10.1002/anie.200462468.

4. Haldeman C.W., Ahern B.S., Johnson K.H. (1997). Supercritical water fuel composition and combustion system. US6010544A.

5. Sato T., Haryu K., Endo T., Shimada M. (1987): High-temperature oxidation of silicon nitride-based ceramics by water vapour. Journal of Materials Science, 22(7), 2635-2640. doi: 10.1007/BF01082156.

6. Kim H.-E., Moorhead A.J. (1990): High-temperature gaseous corrosion of $\mathrm{Si}_{3} \mathrm{~N}_{4}$ in $\mathrm{H}_{2}-\mathrm{H}_{2} \mathrm{O}$ and $\mathrm{Ar}-\mathrm{O}_{2}$ environments. Journal of the American Ceramic Society, 73(10), 3007-3014. doi: 10.1111/j.1151-2916.1990.tb06708.x.

7. Oda K., Yoshio T., Miyamoto Y., Koizumi M. (1993): Hydrothermal corrosion of pure, hot isostatically pressed silicon nitride. Journal of the American Ceramic Society, 76(5), 1365-1368. doi: 10.1111/j.1151-2916.1993.tb03768.x.

8. Proverbio E., Carassiti F. (1996): Low-temperature oxidation of silicon nitride by water in supercritical condition. Journal of the European Ceramic Society, 16(10), 1121-1126. doi: 10.1016/0955-2219(96)82256-4.

9. Seipel B., Nickel K.. (2003): Corrosion of silicon nitride in aqueous acidic solutions: Penetration monitoring. Journal of the European Ceramic Society, 23(4), 595-602. doi: 10.1016/S0955-2219(02)00280-7.

10. Fox D.S., Opila E.J., Nguyen Q.N., Humphrey D.L., Lewton S.M. (2003): Paralinear Oxidation of Silicon Nitride in a Water-Vapor/Oxygen Environment. Journal of the American Ceramic Society, 86(8), 1256-1261. doi: 10.1111/j.1151-2916.2003.tb03461.x.

11. Nickel K.G., Seipel B. (2004): Corrosion penetration monitoring of advanced ceramics in hot aqueous fluids. Materials Research, 7(1), 125-133. doi: 10.1590/S151614392004000100017.

12. Schilm J., Gruner W., Herrmann M., Michael G. (2006): Corrosion of $\mathrm{Si}_{3} \mathrm{~N}_{4}$-ceramics in aqueous solutions Part I: Characterisation of starting materials and corrosion in
$1 \mathrm{~N} \mathrm{H}_{2} \mathrm{SO}_{4}$. Journal of the European Ceramic Society, 26(16), 3909-3917. doi: 10.1016/J.JEURCERAMSOC. 2005.12.001.

13. Blugan G., Wittig D., Kuebler J. (2009): Oxidation and corrosion of silicon nitride ceramics with different sintering additives at 1200 and $1500{ }^{\circ} \mathrm{C}$ in air, water vapour, $\mathrm{SO}_{2}$ and $\mathrm{HCl}$ environments - A comparative study. Corrosion Science, 51(3), 547-555. doi: 10.1016/J.CORSCI.2008. 12.014 .

14. Galusková D., Kašiarová M., Hnatko M., Galusek D., Dusza J., Šajgalík P. (2014): Hydrothermal corrosion and flexural strength of $\mathrm{Si}_{3} \mathrm{~N}_{4}$-based ceramics. Corrosion Science, 85, 94-100. doi: 10.1016/j.corsci.2014.04.005.

15. Galusková D., Hnatko M., Galusek D., Šajgalík P. (2011): Corrosion of structural ceramics under subcritical conditions in aqueous sodium chloride solution and in deionized water. Part I: Dissolution of $\mathrm{Si}_{3} \mathrm{~N}_{4}$-based ceramics. Journal of the American Ceramic Society, 94(9), 3035-3043. doi: 10.1111/j.1551-2916.2011.04553.x.

16. Tatarko P., Kašiarová M., Dusza J., Šajgalík P. (2013): Influence of rare-earth oxide additives on the oxidation resistance of $\mathrm{Si}_{3} \mathrm{~N}_{4}-\mathrm{SiC}$ nanocomposites. Journal of the European Ceramic Society, 33(12), 2259-2268. doi: 10.1016/j.jeurceramsoc.2013.01.008.

17. Opila E.J., Robinson R.C., Fox D.S., Wenglarz R.A., Ferber M.K. (2003): Additive effects on $\mathrm{Si}_{3} \mathrm{~N}_{4}$ oxidation/ volatilization in water vapor. Journal of the American Ceramic Society, 86(8), 1262-1271. doi: 10.1111/j.11512916.2003.tb03462.x.

18. Linck C., Ionescu E., Papendorf B., Galuskova D., Galusek D., Šajgalík P., Riedel R. (2012): Corrosion behavior of silicon oxycarbide-based ceramic nanocomposites under hydrothermal conditions. International Journal of Materials Research, 103(1), 31-39. doi: 10.3139/146.110625.

19. Parcianello G., Bernardo E., Colombo P., Lenčéš Z., Vetrecín M., Šajgalík P., Kašiarová M. (2014): Preceramic polymer-derived SiAlON as sintering aid for silicon nitride. Journal of the American Ceramic Society, 97(11), 34073412. doi: 10.1111/jace.13134.

20. Shetty D.K., Wright I.G., Mincer P.N., Clauer A.H. (1985): Indentation fracture of WC-Co cermets. Journal of Materials Science, 20(5), 1873-1882. doi: 10.1007/ BF00555296.

21. Lindqvist O., Sjöberg J., Hull S., Pompe R. (1991): Structural changes in O'-sialons, $\mathrm{Si}_{2-\mathrm{x}} \mathrm{Al}_{\mathrm{x}} \mathrm{N}_{2-\mathrm{x}} \mathrm{O}_{1+\mathrm{x}}, 0.04 \leq x \leq$ 0.40. Acta Crystallographica Section B Structural Science, 47(5), 672-678. doi: 10.1107/S0108768191004883.

22. Kato K., Inoue Z., Kijima K., Kawada I., Tanaka H., Yamane T. (1975): Structural approach to the problem of oxygen content in alpha silicon nitride. Journal of the American Ceramic Society, 58(3-4), 90-91. doi: 10.1111/ j.1151-2916.1975.tb19564.x.

23. Peuckert M., Greil P. (1987): Oxygen distribution in silicon nitride powders. Journal of Materials Science, 22(10), 3717-3720. doi: 10.1007/BF01161483.

24. Hirao K., Tsuge A., Brito M.E., Kanzaki S. (1993): Preparation of rod-like $\beta-\mathrm{Si}_{3} \mathrm{~N}_{4}$ single crystal particles. Journal of the Ceramic Society of Japan, 101x(1177), 1078-1080. doi: 10.2109/jcersj.101.1078.

25. Morachevsky Y. V., Piryutko M.M. (1956): Solubility of silicic acid. Bulletin of the Academy of Sciences of the USSR Division of Chemical Science, 5(8), 917-923. doi: 10.1007/BF01166404.

26. Perera G., Doremus R.H., Lanford W. (1991): Dissolution 
rates of silicate glasses in water at $\mathrm{pH}$ 7. Journal of the American Ceramic Society, 74(6), 1269-1274. doi: 10.1111/j.1151-2916.1991.tb04096.x.

27. Greil P., Nitzsche R., Friedrich H., Hermel W. (1991): Evaluation of oxygen content on silicon nitride powder surface from the measurement of the isoelectric point Journal of the European Ceramic Society, 7(6), 353-359. doi: 10.1016/0955-2219(91)90058-8.

28. Herrmann M. (2013): Corrosion of silicon nitride materials in aqueous solutions. Journal of the American Ceramic Society, 96(10), 3009-3022. doi: 10.1111/jace.12509.

29. Herrmann M., Schilm J., Michael G., Meinhardt J., Flegler R. (2003): Corrosion of silicon nitride materials in acidic and basic solutions and under hydrothermal conditions. Journal of the European Ceramic Society, 23(4), 585-594. doi: 10.1016/S0955-2219(02)00303-5.

30. Nickel K.G., Däumling U., Weisskopf K. (1993): Hydrothermal reactions of Si3N4. Key Engineering Materials, 89-91, 295-300. doi: 10.4028/www.scientific. net/KEM.89-91.295.

31. Yuan J., Luan X., Riedel R., Ionescu E. (2015): Preparation and hydrothermal corrosion behavior of $\mathrm{Cf} / \mathrm{SiCN}$ and $\mathrm{Cf} /$ SiHfBCN ceramic matrix composites. Journal of the European Ceramic Society, 35(12), 3329-3337. doi: 10.1016/j.jeurceramsoc.2014.12.009. 